\title{
Calculation of Intervertebral Disc Pressure in the Thoracic and Lumbar Spine in Elderly Women with Kyphosis Using a Novel Musculoskeletal Model with Isolated Thoracic Vertebrae and Rib Cage
}

\author{
Jumpei Iida', Naohisa Miyakoshi1 ${ }^{*}$, Michio Hongo', Takehiro Iwami², Ryo Higuchi², \\ Akira Komatsu' ${ }^{2}$, Toshiki Matsunaga ${ }^{3}$, Yoichi Shimada1 \\ ${ }^{1}$ Department of Orthopedic Surgery, Akita University Graduate School of Medicine, Akita, Japan \\ ${ }^{2}$ Department of Mechanical Engineering, Akita University Faculty of Engineering and Resource Science, Akita, Japan \\ ${ }^{3}$ Department of Rehabilitation Medicine, Akita University Hospital, Akita, Japan \\ Email: ^miyakosh@doc.med.akita-u.ac.jp
}

How to cite this paper: Iida, J., Miyakoshi, N., Hongo, M., Iwami, T., Higuchi, R., Komatsu, A., Matsunaga, T. and Shimada, Y. (2019) Calculation of Intervertebral Disc Pressure in the Thoracic and Lumbar Spine in Elderly Women with Kyphosis Using a Novel Musculoskeletal Model with Isolated Thoracic Vertebrae and Rib Cage. Open Journal of Orthopedics, 9, 241-253. https://doi.org/10.4236/ojo.2019.911025

Received: October 10, 2019

Accepted: November 26, 2019

Published: November 29, 2019

Copyright $\odot 2019$ by author(s) and Scientific Research Publishing Inc. This work is licensed under the Creative Commons Attribution International License (CC BY 4.0).

http://creativecommons.org/licenses/by/4.0/

\section{cc) (i) Open Access}

\begin{abstract}
Background: Degeneration of the intervertebral disc is one of the causes of kyphosis. Several biomechanical studies have investigated the mechanisms of development of spinal deformity using simulation models. Realistic musculoskeletal models are helpful for investigating the pathophysiology and changes in internal forces in patients with kyphosis. However, the association between intervertebral disc pressure and kyphosis has not been fully elucidated to date. Purpose: To calculate intervertebral disc pressure in elderly women with kyphosis using a novel and precise thoracolumbar three-dimensional musculoskeletal model. Materials and Method: Ten female patients with a mean age of $80.0 \pm 6.5$ years who visited our hospital for medical examination of osteoporosis were included. The subjects were divided into the normal and kyphosis groups depending on their sagittal vertical axis. Intervertebral disc pressures in the thoracic and lumbar spines of subjects were analyzed by inverse dynamics analysis using a novel three-dimensional musculoskeletal model, and were compared between the groups. Result: Significant differences in lumbar lordosis (LL) were observed between the two groups. Furthermore, the kyphosis group was older and shorter. In the kyphosis group, the upper thoracic vertebrae (T1 - T6) showed significantly higher intervertebral pressure than the normal group. Conclusion: Intervertebral disc pressure in the thoracic and lumbar spines of patients with spinal deformities was evaluated using a novel thoracolumbar three-dimensional musculoskeletal model. Us-
\end{abstract}


ing this novel model with separated thoracic spine and modified muscle path reflecting actual physiological curvature, disc pressure closer to the realistic condition was obtained. Intervertebral disc pressure in the upper thoracic spine in the kyphosis group was significantly increased compared with that in the normal group. Moreover, intervertebral disc pressures in the upper thoracic spine correlated negatively with $L L$.

\section{Keywords}

Intervertebral Disc Pressure, Three-Dimensional Musculoskeletal Model, Adult Spinal Deformity, Anybody Modeling System

\section{Introduction}

Kyphosis progresses with advancing age [1], and has been found to be associated with multiple health-related problems, including back pain [2], imbalance, a tendency to fall [3] [4] [5], gastroesophageal disorders [6], multifaceted disorders such as mental depression [7], and decrease in health-related quality of life [8]. The possible causes of kyphosis are degeneration of intervertebral discs, development of vertebral fractures, and decrease in trunk muscle strength [9]. Hence, it is important to understand the mechanical behavior of the intervertebral disc as a part of the entire spinal column in order to understand the etiology of spinal deformity. However, the mechanisms of progression of kyphosis other than due to the development of vertebral fractures are still unclear.

Several biomechanical studies have used simulation models to investigate the mechanisms of the development of spinal deformity [10] [11] [12]. Most of these studies focused mainly on vertebral body stress rather than intervertebral disc pressure. In vitro studies using human or animal cadavers have evaluated the internal forces in vertebral bodies and intervertebral discs [13] [14] [15] [16]. Disc pressure has also been measured in vivo during various movements and lifting operations, by inserting a pressure sensor inside the intervertebral disc [17] [18] [19] [20]. However, the in vivo procedures are basically invasive, especially for healthy subjects. Besides, the majority of these studies were performed mainly on the lumbar spine. Therefore, evaluation of intervertebral disc pressure of the entire spinal column, to determine how kyphosis occurs and progresses, is necessary. Realistic musculoskeletal models might be helpful for investigating the pathophysiology and changes in internal forces in patients with kyphosis.

Recently, several biomechanical studies using a musculoskeletal model of the entire spine, including the rib cage or whole body, have been developed [10] [21] [22] [23] [24]. We also developed a novel musculoskeletal model of the entire spinal column, which was modified from the original model for the lumbar spine, which included the thoracic cage as one rigid body [23]. The predicted intervertebral disc pressure of the spinal column as a whole with this model was validated to show the accuracy of measurements including the thoracic spine. Since 
previous studies using a musculoskeletal model for the whole spine focused on the development of vertebral fractures [10] [25] or the effect of various movements on disc pressure [22], the association between intervertebral disc pressure and kyphosis has not been fully elucidated to date. The purpose of this study was to calculate intervertebral disc pressure in elderly women with kyphosis using a novel thoracolumbar three-dimensional musculoskeletal model.

\section{Materials and Methods}

\subsection{Participants}

Ten female participants with osteoporosis were recruited from among postmenopausal women who visited our outpatient clinic for the purpose of medical examination of osteoporosis. Participants were included on the basis that they had been diagnosed with primary osteoporosis requiring treatment. All participants were housewives without experiences of heavy work, and were ambulatorywithout any complaints of back pain. Individuals with histories of spinal surgery, vertebroplasty/kyphoplasty, and multiple vertebral fractures $(\geq 2)$ were excluded. The ethics committee of our institute approved this study protocol.

\subsection{Imaging}

Lateral radiographs of the whole spine, including the pelvis, with both hands placed on the clavicle, were taken in the relaxed standing position. The following parameters were measured on the radiographs: sagittal vertical axis (SVA: Horizontal distance from the $\mathrm{C} 7$ plumb line originating at the middle of the $\mathrm{C} 7$ vertebral body to the posterior superior endplate of S1), lumbar lordosis (LL: Cobb angle from the upper endplate of L1 to the lower endplate of S1), and thoracic kyphosis (TK: Cobb angle from the upper endplate of T4 to the lower endplate of T12).

\subsection{Biomechanical Model}

The novel thoracolumbar spine model used in this study was constructed with the commercially available AnyBody Modeling System software (AMS. V.6.0.5.4379) (AnyBody Technology, Alborg, Denmark) [23]. The original model was constructed based on a generic lumbar spine model [26], although the thorax was constructed as one rigid unit. In the novel model, the thorax was divided into 33 parts, including 12 thoracic vertebrae, 10 pairs of articulated ribs, and the sternum. Trunk muscles, including 15 individual muscles and 328 fascicles, were newly defined. The origin and insertion points of the muscles and muscle cross sections were decided based on magnetic resonance imaging (MRI) data [27]. The muscle path were determined using a previously described wrapping method [28] that follows the geometric shape of the figure. The model was previously validated for accuracy of the predicted intervertebral disc pressure using inverse dynamics analysis [23], and was shown to accurately predict interverte- 
bral disc pressure in comparison with previous in vivo data [17] [18] [29]. The constructed model is shown in Figure 1.

\subsection{Input of Vertebral Geometry}

The vertebral centroid was determined to be located at the intersection of the diagonal lines of the quadrilateral formed by each vertebral body in lateral standing radiographs. Next, the centroids of vertebral bodies from C7 to S1 were plotted on the $\mathrm{x}$-axis and $\mathrm{y}$-axis directions in the sagittal plane (Figure 2). Body weight and height for each patient were input into the model.

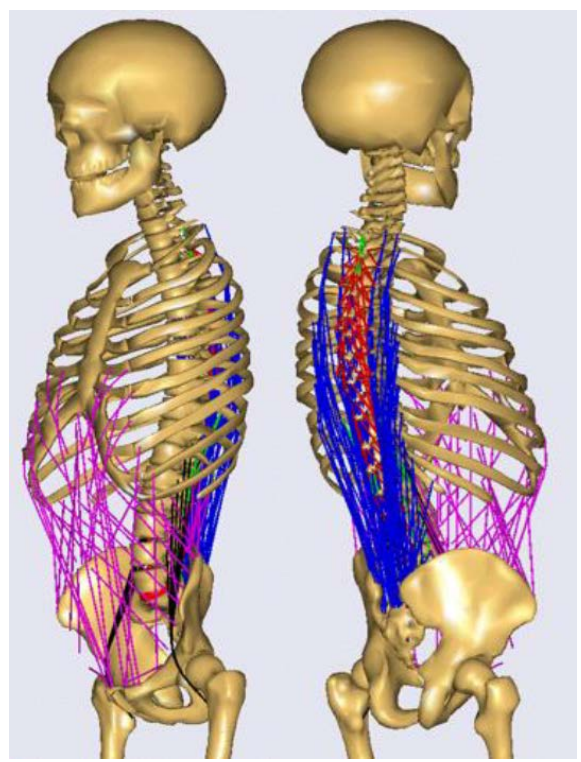

Figure 1. Overview of the novel musculoskeletal spine model. The thorax in the novel model was divided into separated thoracic vertebrae, articulated ribs, and the sternum. The origin and insertion points of the muscle path and muscle cross section were decided based on MRI data. The muscle paths were determined using the wrapping method.
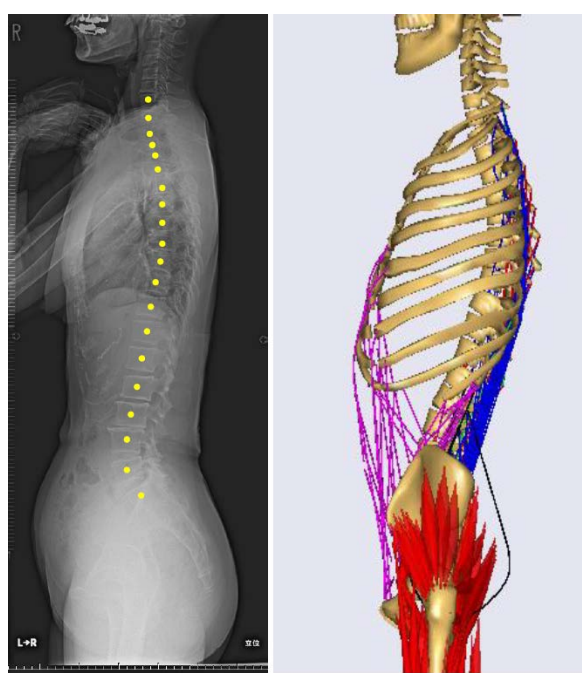

Figure 2. The centroids of vertebral bodies measured from lateral standing radiographs were plotted in the $\mathrm{x}$-axis and $\mathrm{y}$-axis directions in the sagittal plane. 


\subsection{Conditions for Calculation of Intervertebral Disc Pressure}

The patients were asked to stand still with their hands on their clavicles, and the pelvis and sacrum were fixed in the sagittal plane using three-dimensional coordinates. In each subject, inverse dynamics analysis was performed in the model to estimate joint movement and muscle tension, and intervertebral disc compression force was calculated from these values. Intervertebral disc compression force was converted to intervertebral disc pressure by substituting the correction factor of a previously reported equation [30].

\subsection{Statistical Analysis}

Statistical analyses were performed with SPSS $^{\circledR}$ software version 24 (IBM Corp., Armonk, NY, USA). The correlation coefficient between spinal column alignment, intervertebral disc pressure, and height and weight was analyzed with Pearson's test. Comparisons between the two groups were made using the unpaired test. A P-value of $<0.05$ was considered statistically significant.

\section{Results}

Demographic data for all the patients are presented in Table 1. The average age

Table 1. Demographic data of the study subjects $(n=10)$.

\begin{tabular}{cc}
\hline Variables & Values $($ mean \pm SD) \\
\hline Age $($ years $)$ & $80.0 \pm 6.5$ \\
Height $(\mathrm{cm})$ & $147.0 \pm 7.1$ \\
Weight $(\mathrm{kg})$ & $44.5 \pm 9.2$ \\
TK $\left(^{\circ}\right)$ & $38.0 \pm 9.9$ \\
LL $\left(^{\circ}\right)$ & $42.0 \pm 13.2$ \\
SVA $(\mathrm{mm})$ & $38.5 \pm 19.1$ \\
T1-2 $(\mathrm{N})$ & $34.0 \pm 20.3$ \\
T2-3 $(\mathrm{N})$ & $31.9 \pm 23.2$ \\
T3-4 $(\mathrm{N})$ & $46.8 \pm 38.0$ \\
T4-5 $(\mathrm{N})$ & $68.7 \pm 42.7$ \\
T5-6 $(\mathrm{N})$ & $84.8 \pm 51.0$ \\
T6-7 $(\mathrm{N})$ & $104.3 \pm 58.2$ \\
T7-8 $(\mathrm{N})$ & $131.0 \pm 58.8$ \\
T8-9 $(\mathrm{N})$ & $146.5 \pm 62.4$ \\
T9-10 $(\mathrm{N})$ & $186.6 \pm 67.0$ \\
T10-11 $(\mathrm{N})$ & $273.2 \pm 84.1$ \\
T11-12 $(\mathrm{N})$ & $314.1 \pm 85.1$ \\
T12-L1 $(\mathrm{N})$ & $330.0 \pm 90.4$ \\
L1-2 $(\mathrm{N})$ & $353.2 \pm 77.0$ \\
L2-3 $(\mathrm{N})$ & $362.0 \pm 89.5$ \\
L3-4 $(\mathrm{N})$ & $321.9 \pm 88.3$ \\
L4-5 $(\mathrm{N})$ & $422.6 \pm 96.3$ \\
L5-S $(\mathrm{N})$ & $493.2 \pm 96.9$ \\
\hline (0) & \\
\hline
\end{tabular}

TK: thoracic kyphosis $\left({ }^{\circ}\right)$, LL: lumbar lordosis $\left({ }^{\circ}\right)$, SVA: sagittal vertical axis $(\mathrm{mm})$, The values for the individual spinal levels denote indicate intervertebral disc pressure (N: Newton). 
of the patients was $80.0 \pm 6.5$ years. The spinopelvic parameters indicated moderate deterioration of alignment. One vertebral fracture each was seen in four of the study subjects. The calculated intervertebral disc pressure at each spinal level increased in a caudal direction.

The patients were divided into two groups based on SVA. Patients with an SVA of more than $40 \mathrm{~mm}$ were defined as the kyphosis group, and those in whom SVA was less than $40 \mathrm{~mm}$ as the normal group [31]. Significant differences in LL were observed between the two groups. Furthermore, the kyphosis group was older and shorter (Table 2).

In the kyphosis group, the disc spaces between the upper thoracic vertebrae of T1-2, T2-3, T3-4, T4-5 and T5-6 showed significantly higher intervertebral pressures than the normal group (Figure 3 ).

Correlation coefficients between intervertebral disc pressure and sagittal spinal alignment are presented in Table 3. Intervertebral disc pressures significantly positively correlated with SVA from T1-2 to T6-7, and negatively correlated with LL from T3-4 to T5-6. Both findings were mainly found in the upper thoracic vertebrae.

\section{Discussion}

This study examined intervertebral disc pressure of the entire spine, including the thoracic and lumbar spine, and evaluated the effect of kyphosis on intervertebral disc pressure using a novel musculoskeletal model developed at our institution [23]. One of the characteristics of this new model is that the thoracic cage, which was originally a rigid structure in a previous model [26], was divided into 12 vertebrae, 10 pairs of articulated ribs, and the sternum. In addition, geometric muscle structures were constructed based on our own precise anatomical data obtained using computed tomography and MRI [27]. Initially, the pathways of the muscles were defined as straight lines between the origin and insertion of the muscle. However, since the actual muscles of the trunk often turn around bony structures or soft tissues, the muscle paths were re-constructed using a wrapping method, which reproduces the muscle path, closely reflecting actual physiological curvature around the underlying bony structures and soft tissues [28]. Then, intervertebral disc pressures that were calculated with this model under several

Table 2. Comparison of spinopelvic parameters between the two groups.

\begin{tabular}{cccc}
\hline & $\begin{array}{c}\mathrm{SVA} \geq 40^{\circ} \\
(\mathrm{n}=4)\end{array}$ & $\begin{array}{c}\mathrm{SVA}<40^{\circ} \\
(\mathrm{n}=6)\end{array}$ & p value \\
\hline Age (years) & $85.5 \pm 2.8$ & $77.0 \pm 6.1$ & 0.05 \\
Height $(\mathrm{kg})$ & $141.5 \pm 3.0$ & $152.0 \pm 5.3$ & 0.01 \\
Weight $(\mathrm{cm})$ & $38.0 \pm 2.2$ & $52.5 \pm 7.0$ & 0.01 \\
$\mathrm{TK}\left({ }^{\circ}\right)$ & $38.5 \pm 8.1$ & $33.0 \pm 10.9$ & $\mathrm{Ns}$ \\
$\mathrm{LL}\left({ }^{\circ}\right)$ & $31.0 \pm 3.6$ & $42.0 \pm 11.4$ & 0.02 \\
\hline
\end{tabular}

SVA: sagittal vertical axis (mm), TK: thoracic kyphosis $\left({ }^{\circ}\right)$, LL: lumbar lordosis $\left({ }^{\circ}\right)$. 
Table 3. Pearson's correlation coefficients between intervertebral disc pressure and sagittal parameters.

\begin{tabular}{cccc}
\hline & SVA & TK & LL \\
\hline T1-2 & $0.70^{*}$ & 0.27 & -0.44 \\
T2-3 & $0.69^{*}$ & 0.13 & -0.55 \\
T3-4 & $0.70^{*}$ & 0.08 & $-0.61^{*}$ \\
T4-5 & $0.70^{*}$ & -0.60 & $-0.63^{*}$ \\
T5-6 & $0.69^{*}$ & -0.27 & $-0.61^{*}$ \\
T6-7 & $0.64^{*}$ & -0.06 & -0.58 \\
T7-8 & 0.61 & -0.12 & -0.49 \\
T8-9 & 0.59 & -0.15 & -0.45 \\
T9-10 & 0.56 & -0.17 & -0.39 \\
T10-11 & 0.53 & -0.24 & -0.38 \\
T11-12 & 0.52 & -0.17 & -0.37 \\
T12-L1 & 0.48 & -0.22 & -0.31 \\
L1-2 & 0.29 & -0.21 & -0.05 \\
L2-3 & 0.48 & -0.23 & -0.24 \\
L3-4 & 0.27 & -0.20 & 0.00 \\
L4-5 & 0.28 & -0.01 & -0.03 \\
L5-S & 0.34 & -0.24 & -0.12 \\
\hline
\end{tabular}

SVA: sagittal vertical axis $(\mathrm{mm})$, TK: thoracic kyphosis $\left({ }^{\circ}\right)$, LL: lumbar lordosis $\left({ }^{\circ}\right),\left({ }^{*} \mathrm{p}<0.05\right)$.

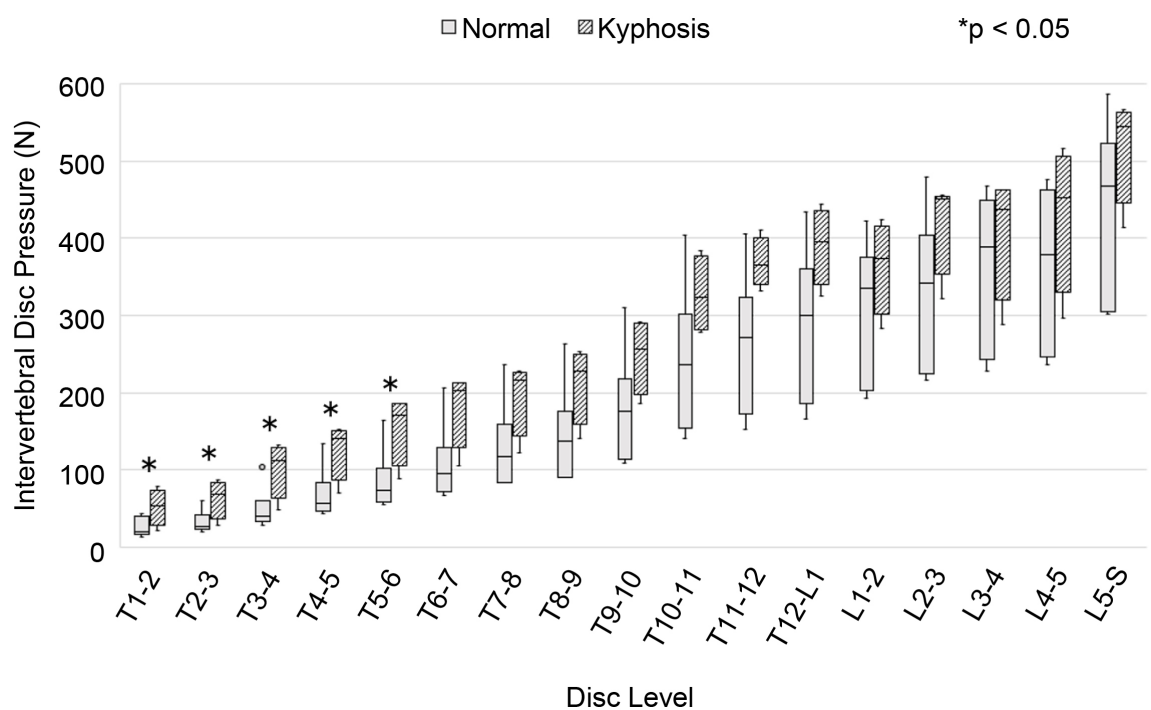

Figure 3. Comparison of intervertebral disc pressure between the groups.

conditions of daily activities were validated and demonstrated to accurately predict the load [23]. Therefore, the results obtained in this study are considered realistic and reliable for estimating intervertebral disc pressure under various conditions of spinal alignment, including kyphosis.

Biomechanical studies evaluating the internal forces in the intervertebral disc are mostly performed for the lumbar spine, with measurements performed in vivo, using cadaver studies, or by model simulation. Numerous cadaver studies 
have been conducted on the load and kinematics of vertebral bodies or intervertebral discs [13] [14] [15] [16] [32]. Brown et al. reported the effect of functional spinal unit instability on lumbar disc degeneration using cadavers [13]. Anderson et al. investigated intervertebral disc pressures of the thoracic spine and demonstrated the effect of the rib cage and follower load [15]. Liebsch et al. also showed the effect of follower load on the motion of the thoracic spine using an entire rib cage specimen, trying to simulate physiological loading conditions [32]. Although these in vitro studies using cadavers demonstrated accurate measurement of disc pressure and kinematic data, the cadaveric spine does not completely reflect in vivo conditions in terms of the effects of muscle tone or intra-thoracic and abdominal pressure. Besides, in vitro cadaver studies are generally performed with isolated thoracic spines with or without rib cages.

Several reports have described measurement of changes in in vivo forces due to postural changes by a method involving actual insertion of a pressure sensor in the intervertebral disc [17] [18] [19] [20]. Nachemson et al. first reported intervertebral disc pressure in various postures, such as standing, sitting and supine positions, in 1964 [20]. Wilke et al. measured the intervertebral disc pressure in daily life in various sitting postures and with lifting of heavy weights [19] [29]. Sato et al. reported that the internal disc pressure in degenerated L4-5 discs was significantly reduced compared with that of normal discs [17]. Polga et al. measured intervertebral disc pressure in the thoracic vertebrae and showed that changes in the lumbar spine with posture differed from those previously reported, depending on the posture [18]. These in vivo studies are considerably important to understand the fundamental mechanisms of the intact spine. However, these experiments are increasingly difficult to reproduce due to their invasiveness for healthy subjects and the associated ethical issues. Therefore, a validated musculoskeletal model comparable to these previous studies is helpful to expand opportunities for investigation of the biomechanical behavior of the complete spine. The model employed in the present study was compared with these previous in vivo data [17] [18] [20], which showed that the predicted value with this model showed significant correlation with the literature value [23]. Further, while the results of intervertebral disc pressure in the validation study were calculated for healthy subjects, the present results demonstrated the value in patients with kyphosis for the first time.

As a less invasive strategy for assessment of intervertebral disc dynamics, analyses using a finite element model or musculoskeletal models are being actively developed. A majority of the studies on intervertebral discs were conducted on the lumbar spine [33] [34] [35] [36]. Few studies investigated the whole spine to determine the association between kyphosis and spinal loads in vertebral bodies and intervertebral discs [10] [12] [37]. Okamoto et al. constructed a kyphosis model with vertebral fractures, and concluded that presence of a pre-existing vertebral fracture causes an increase in stress on adjacent vertebrae [10]. Briggs et al. reported the effects of increased kyphosis on the loading profile of the thoracolumbar spine by constructing a two-dimensional biomechanical model us- 
ing the radiographic data from patients with kyphosis, and concluded that increases in thoracic kyphosis were associated with significantly higher multi-segmental spinal load and trunk muscle forces in the upright stance [12]. Ignasiak et al. investigated the effects of muscle aging and sarcopenia on spinal load using generic AnyBody musculoskeletal multibody modeling, which was similar to our original model [24]. In their study which highlighted the effect of muscle or sarcopenia, forward flexion of the whole spine was simulated to observe changes in spinal load. The conclusion from these previous studies was that kyphosis increases intervertebral load, moving it in a more cranial direction, which was a similar trend to the results of the present study. In addition, these previous musculoskeletal models used geometric data from a single typical human body, while the present study used the data from 10 subjects with different spinal alignments and input the data in the model. Therefore, this study might be the introduction of patient specific biomechanical evaluation before treatment in patients with kyphosis.

There are several limitations to this study. First, the number of subjects was small. Since this study demonstrated preliminary results, further research would be expected based on the findings from this study. Second, the data were obtained only in the standing position without any movement. However, the results can serve as the basis for future study of whole thoracic and lumbar spine under dynamic conditions in patients with kyphosis. Third, in this analysis, coronal deformity and pelvic alignment were not considered. Sagittal spinopelvic alignment is a significant factor when considering the relationship between the health-related quality of life and spinal alignment in adult patients with spinal deformity [31] [38]. Further, pelvic tilt and lower limb compensation are very important in spinal alignment studies. However, this study focused on establishing a simple method to evaluate the effect of progression of kyphosis with the position of the pelvis fixed. Since this model has a three-dimensional structure, it might be possible to evaluate pelvic and coronal alignment and the connection with the lower limbs in future studies.

\section{Conclusion}

Intervertebral disc pressure in the thoracic and lumbar spines of patients with spinal deformities was evaluated using a novel three-dimensional thoracolumbar musculoskeletal model. Using this novel model with separated thoracic spine and modified muscle path reflecting actual physiological curvature, disc pressure closer to the realistic condition was obtained. Intervertebral disc pressure in the upper thoracic spine in the kyphosis group was significantly higher than that in the normal group. Moreover, intervertebral disc pressure correlated negatively with LL in the upper thoracic spine.

\section{Ethical Considerations}

The ethics committee of our institute approved the study protocol. All subjects provided written informed consent before participating in this study. 


\section{Conflicts of Interest}

The authors declare no conflicts of interest regarding the publication of this paper.

\section{References}

[1] Kasukawa, Y., Miyakoshi, N., Hongo, M., Ishikawa, Y., Kudo, D., Suzuki, M., Mizutani, T., Kimura, R., Ono, Y. and Shimada, Y. (2017) Age-Related Changes in Muscle Strength and Spinal Kyphosis Angles in an Elderly Japanese Population. Clinical Interventions in Aging, 12, 413-420. https://doi.org/10.2147/CIA.S113352

[2] Glassman, S.D., Berven, S., Bridwell, K., Horton, W. and Dimar, J.R. (2005) Correlation of Radiographic Parameters and Clinical Symptoms in Adult Scoliosis. Spine (Phila Pa 1976), 30, 682-688. https://doi.org/10.1097/01.brs.0000155425.04536.f7

[3] Kasukawa, Y., Miyakoshi, N., Hongo, M., Ishikawa, Y., Noguchi, H., Kamo, K., Sasaki, H., Murata, K. and Shimada, Y. (2010) Relationships between Falls, Spinal Curvature, Spinal Mobility and Back Extensor Strength in Elderly People. Journal of Bone and Mineral Metabolism, 28, 82-87. https://doi.org/10.1007/s00774-009-0107-1

[4] Ishikawa, Y., Miyakoshi, N., Kasukawa, Y., Hongo, M. and Shimada, Y. (2009) Spinal Curvature and Postural Balance in Patients with Osteoporosis. Osteoporosis International, 20, 2049-2053. https://doi.org/10.1007/s00198-009-0919-9

[5] Milne, J.S. and Lauder, I.J. (1974) Age Effects in Kyphosis and Lordosis in Adults. Annals of Human Biology, 1, 327-337. https://doi.org/10.1080/03014467400000351

[6] Miyakoshi, N., Kasukawa, Y., Sasaki, H., Kamo, K. and Shimada, Y. (2009) Impact of Spinal Kyphosis on Gastroesophageal Reflux Disease Symptoms in Patients with Osteoporosis. Osteoporosis International, 20, 1193-1198. https://doi.org/10.1007/s00198-008-0777-x

[7] Silverman, S.L., Minshall, M.E., Shen, W., Harper, K.D., Xie, S. and Health-Related Quality of Life Subgroup of the Multiple Outcomes of Raloxifene Evaluation, S. (2001) The Relationship of Health-Related Quality of Life to Prevalent and Incident Vertebral Fractures in Postmenopausal Women with Osteoporosis: Results from the Multiple Outcomes of Raloxifene Evaluation Study. Arthritis \& Rheumatology, 44, 2611-2619. https://doi.org/10.1002/1529-0131(200111)44:11<2611::AID-ART441>3.0.CO;2-N

[8] Miyakoshi, N., Itoi, E., Kobayashi, M. and Kodama, H. (2003) Impact of Postural Deformities and Spinal Mobility on Quality of Life in Postmenopausal Osteoporosis. Osteoporosis International, 14, 1007-1012. https://doi.org/10.1007/s00198-003-1510-4

[9] Kado, D.M. (2009) The Rehabilitation of Hyperkyphotic Posture in the Elderly. European Journal of Physical and Rehabilitation Medicine, 45, 583-593.

[10] Okamoto, Y., Murakami, H., Demura, S., Kato, S., Yoshioka, K., Hayashi, H., Sakamoto, J., Kawahara, N. and Tsuchiya, H. (2015) The Effect of Kyphotic Deformity Because of Vertebral Fracture: A Finite Element Analysis of a 10 Degrees and 20 Degrees Wedge-Shaped Vertebral Fracture Model. The Spine Journal, 15, 713-720. https://doi.org/10.1016/j.spinee.2014.11.019

[11] Tawara, D., Sakamoto, J., Murakami, H., Kawahara, N., Oda, J. and Tomita, K. (2010) Mechanical Evaluation by Patient-Specific Finite Element Analyses Demonstrates Therapeutic Effects for Osteoporotic Vertebrae. Journal of the Mechanical Behavior of Biomedical Materials, 3, 31-40. 
https://doi.org/10.1016/j.jmbbm.2009.03.001

[12] Briggs, A.M., van Dieen, J.H., Wrigley, T.V., Greig, A.M., Phillips, B., Lo, S.K. and Bennell, K.L. (2007) Thoracic Kyphosis Affects Spinal Loads and Trunk Muscle Force. Physical Therapy, 87, 595-607. https://doi.org/10.2522/ptj.20060119

[13] Brown, M.D., Holmes, D.C. and Heiner, A.D. (2002) Measurement of Cadaver Lumbar Spine Motion Segment Stiffness. Spine (Phila Pa 1976), 27, 918-922. https://doi.org/10.1097/00007632-200205010-00006

[14] Pollintine, P., Przybyla, A.S., Dolan, P. and Adams, M.A. (2004) Neural Arch LoadBearing in Old and Degenerated Spines. Journal of Biomechanics, 37, 197-204. https://doi.org/10.1016/S0021-9290(03)00308-7

[15] Anderson, D.E., Mannen, E.M., Sis, H.L., Wong, B.M., Cadel, E.S., Friis, E.A. and Bouxsein, M.L. (2016) Effects of Follower Load and Rib Cage on Intervertebral Disc Pressure and Sagittal Plane Curvature in Static Tests of Cadaveric Thoracic Spines. Journal of Biomechanics, 49, 1078-1084. https://doi.org/10.1016/j.jbiomech.2016.02.038

[16] Dolan, P., Luo, J., Pollintine, P., Landham, P.R., Stefanakis, M. and Adams, M.A. (2013) Intervertebral Disc Decompression Following Endplate Damage: Implications for Disc Degeneration Depend on Spinal Level and Age. Spine (Phila Pa 1976), 38, 1473-1481. https://doi.org/10.1097/BRS.0b013e318290f3cc

[17] Sato, K., Kikuchi, S. and Yonezawa, T. (1999) In Vivo Intradiscal Pressure Measurement in Healthy Individuals and in Patients with Ongoing Back Problems. Spine (Phila Pa 1976), 24, 2468-2474.

https://doi.org/10.1097/00007632-199912010-00008

[18] Polga, D.J., Beaubien, B.P., Kallemeier, P.M., Schellhas, K.P., Lew, W.D., Buttermann, G.R. and Wood, K.B. (2004) Measurement of in Vivo Intradiscal Pressure in Healthy Thoracic Intervertebral Discs. Spine (Phila Pa 1976), 29, 1320-1324. https://doi.org/10.1097/01.BRS.0000127179.13271.78

[19] Wilke, H.J., Neef, P., Caimi, M., Hoogland, T. and Claes, L.E. (1999) New in Vivo Measurements of Pressures in the Intervertebral Disc in Daily Life. Spine, 24, 755-762. https://doi.org/10.1097/00007632-199904150-00005

[20] Nachemson, A. and Morris, J.M. (1964) In Vivo Measurements of Intradiscal Pressure. Discometry, a Method for the Determination of Pressure in the Lower Lumbar Discs. The Journal of Bone and Joint Surgery. American Volume, 46, 1077-1092. https://doi.org/10.2106/00004623-196446050-00012

[21] Hajihosseinali, M., Arjmand, N., Shirazi-Adl, A., Farahmand, F. and Ghiasi, M.S. (2014) A Novel Stability and Kinematics-Driven Trunk Biomechanical Model to Estimate Muscle and Spinal Forces. Medical Engineering \& Physics, 36, 1296-1304. https://doi.org/10.1016/j.medengphy.2014.07.009

[22] Bruno, A.G., Bouxsein, M.L. and Anderson, D.E. (2015) Development and Validation of a Musculoskeletal Model of the Fully Articulated Thoracolumbar Spine and Rib Cage. Journal of Biomechanical Engineering, 137, Article ID: 081003. https://doi.org/10.1115/1.4030408

[23] Higuchi, R., Komatsu, A., Iida, J., Iwami, T. and Shimada, Y. (2019) Construction and Validation under Dynamic Conditions of a Novel Thoracolumbar Spine Model with Defined Muscle Paths Using the Wrapping Method. Journal of Biomechanical Science and Engineering, 14, 18-00432-00418-00432. https://doi.org/10.1299/jbse.18-00432

[24] Ignasiak, D., Valenzuela, W., Reyes, M. and Ferguson, S.J. (2018) The Effect of Muscle Ageing and Sarcopenia on Spinal Segmental Loads. European Spine Journal, 
27, 2650-2659. https://doi.org/10.1007/s00586-018-5729-3

[25] Bruno, A.G., Burkhart, K., Allaire, B., Anderson, D.E. and Bouxsein, M.L. (2017) Spinal Loading Patterns from Biomechanical Modeling Explain the High Incidence of Vertebral Fractures in the Thoracolumbar Region. Journal of Bone and Mineral Research, 32, 1282-1290. https://doi.org/10.1002/jbmr.3113

[26] de Zee, M., Hansen, L., Wong, C., Rasmussen, J. and Simonsen, E.B. (2007) A Generic Detailed Rigid-Body Lumbar Spine Model. Journal of Biomechanics, 40, 1219 1227. https://doi.org/10.1016/j.jbiomech.2006.05.030

[27] Iwami, T., Komatsu, A., Otaka, K., Miura, H., Hatakeyama, K., Shimada, Y. and Kobayashi, Y. (2017) Construction and Validation of a Three-Dimensional Trunk Musculoskeletal Model by Using Data from Computed Tomography (CT) and Magnetic Resonance Imaging (MRI). Transactions of the JSME, 83, 16-00318. (In Japanese) https://doi.org/10.1299/transjsme.16-00318

[28] Desailly, E., Sardain, P., Khouri, N., Yepremian, D. and Lacouture, P. (2010) The Convex Wrapping Algorithm: A Method for Identifying Muscle Paths Using the Underlying Bone Mesh. Journal of Biomechanics, 43, 2601-2607.

https://doi.org/10.1016/j.jbiomech.2010.05.005

[29] Wilke, H., Neef, P., Hinz, B., Seidel, H. and Claes, L. (2001) Intradiscal Pressure Together with Anthropometric Data-A Data Set for the Validation of Models. Clinical Biomechanics (Bristol, Avon), 16, S111-S126. https://doi.org/10.1016/S0268-0033(00)00103-0

[30] Dreischarf, M., Rohlmann, A., Zhu, R., Schmidt, H. and Zander, T. (2013) Is It Possible to Estimate the Compressive Force in the Lumbar Spine from Intradiscal Pressure Measurements? A Finite Element Evaluation. Medical Engineering \& Physics, 35, 1385-1390. https://doi.org/10.1016/j.medengphy.2013.03.007

[31] Schwab, F., Ungar, B., Blondel, B., Buchowski, J., Coe, J., Deinlein, D., DeWald, C., Mehdian, H., Shaffrey, C., Tribus, C. and Lafage, V. (2012) Scoliosis Research Society-Schwab Adult Spinal Deformity Classification: A Validation Study. Spine (Phila Pa 1976), 37, 1077-1082. https://doi.org/10.1097/BRS.0b013e31823e15e2

[32] Liebsch, C., Graf, N. and Wilke, H.J. (2018) The Effect of Follower Load on the Intersegmental Coupled Motion Characteristics of the Human Thoracic Spine: An in Vitro Study Using Entire Rib Cage Specimens. Journal of Biomechanics, 78, 36-44. https://doi.org/10.1016/j.jbiomech.2018.06.025

[33] Wang, S., Park, W.M., Kim, Y.H., Cha, T., Wood, K. and Li, G. (2014) In Vivo Loads in the Lumbar L3-4 Disc during a Weight Lifting Extension. Clinical Biomechanics (Bristol, Avon), 29, 155-160.

https://doi.org/10.1016/j.clinbiomech.2013.11.018

[34] Goto, K., Tajima, N., Chosa, E., Totoribe, K., Kuroki, H., Arizumi, Y. and Arai, T. (2002) Mechanical Analysis of the Lumbar Vertebrae in a Three-Dimensional Finite Element Method Model in Which Intradiscal Pressure in the Nucleus Pulposus Was Used to Establish the Model. Journal of Orthopaedic Science, 7, 243-246. https://doi.org/10.1007/s007760200040

[35] Lavecchia, C.E., Espino, D.M., Moerman, K.M., Tse, K.M., Robinson, D., Lee, P.V.S. and Shepherd, D.E.T. (2018) Lumbar Model Generator: A Tool for the Automated Generation of a Parametric Scalable Model of the Lumbar Spine. Journal of the Royal Society Interface, 15, 1-13. https://doi.org/10.1098/rsif.2017.0829

[36] Kuo, C.S., Hu, H.T., Lin, R.M., Huang, K.Y., Lin, P.C., Zhong, Z.C. and Hseih, M.L. (2010) Biomechanical Analysis of the Lumbar Spine on Facet Joint Force and Intradiscal Pressure-A Finite Element Study. BMC Musculoskeletal Disorders, 11, 151. 
https://doi.org/10.1186/1471-2474-11-151

[37] Briggs, A.M., Wrigley, T.V., van Dieen, J.H., Phillips, B., Lo, S.K., Greig, A.M. and Bennell, K.L. (2006) The Effect of Osteoporotic Vertebral Fracture on Predicted Spinal Loads in Vivo. European Spine Journal, 15, 1785-1795.

https://doi.org/10.1007/s00586-006-0158-0

[38] Schwab, F., Lafage, V., Patel, A. and Farcy, J.P. (2009) Sagittal Plane Considerations and the Pelvis in the Adult Patient. Spine (Phila Pa 1976), 34, 1828-1833.

https://doi.org/10.1097/BRS.0b013e3181a13c08 